\title{
IDENTIFYING RESIDUAL PHYSICAL AND EMOTIONAL SYMPTOMS IN PATIENTS WITH INACTIVE JUVENILE IDIOPATHIC ARTHRITIS
}

José Gerson Gestler ${ }^{1}$, Aline Maria de Oliveira Rocha ${ }^{1, \star}$, Annelyse de Araújo Pereira ${ }^{1}$, Maria Teresa Terreri ${ }^{1}$, Claudio Arnaldo Len ${ }^{1}$

1.Universidade Federal de São Paulo, São Paulo (SP), Brazil.

*Corresponding author: alinemorocha6@gmail.com

\section{BACKGROUND}

Juvenile idiopathic arthritis (JIA) is an inflammatory disease that compromises the patient's quality of life with conditions that can extend into adulthood, such as limitations, noninflammatory pain, fatigue, short stature, in addition to social, emotional and educational issues. Approximately $20 \%$ to $30 \%$ of patients with JIA may have limitations in daily activities and impaired quality of life and health. Based on these propositions, we aimed to identify the main residual symptoms of patients without disease activity followed up in a tertiary pediatric rheumatology service.

\section{METHODS}

Medical records of 503 patients with a definitive diagnosis of JIA and who were under 18 years old, were analyzed, from which those who did not have activity of joint, eye disease, systemic manifestations or laboratory changes were selected. for at least 6 months, with or without the use of medication at the time of the research.

\section{RESULTS}

It was possible to identify that of the total number of patients with JIA, 117 were in the inactive phase of the disease and 76 (65\%; $95 \% \mathrm{Cl}[53.9 \% ; 76.1 \%])$ had no symptoms, while 41 (35\%; 95\% Cl [23.9\%; 46.1\%]) had some residual symptom, such as arthralgia (17.9\%), joint movement limitation (1.7\%), 5 (4.3\%) emotional disorders and extra-articular pain (1.8\%), among other nonspecific complaints. Subsequently, the pediatric quality of life inventory (PedsQL 4.0) was applied by telephone, with the aim of assessing the presence of other symptoms not reported in consultations. It was possible to contact 71 patients who reported 219 complaints involved as general tiredness in $24 \%, 95 \% \mathrm{Cl}(14 \% ; 33.9 \%)$; sleep-related fatigue in $31 \%$ of patients $95 \% \mathrm{Cl}(20.2 \%$; $41.7 \%)$; mental tiredness in 37\%, 95\% Cl (25.4\%; 47.8\%); physical capacity reduced by $29 \%, 95 \% \mathrm{Cl}(29.4 \%$; $52.3 \%$ ); emotional change in $62 \%$ with $95 \% \mathrm{Cl}(50.7 \%$; $73.3 \%)$; socialization problems in $15 \%, 95 \% \mathrm{Cl}(7.1 \% ; 23.9 \%)$ and school problems in $82 \%$ of patients $95 \% \mathrm{Cl}$ (72.7\%; 90.7\%).

\section{CONCLUSION}

There was a higher-than-expected prevalence of residual symptoms in JIA patients without disease activity, which demonstrated impairment in activities of daily living. The health of these patients involves issues in addition to expected manifestations of the disease, such as arthritis, which can be identified more objectively and early. through the use of specific tools. These findings reinforce the importance of treatment support by a multidisciplinary team offering the patient conditions for better well-being despite chronic illness.

\section{KEYWORDS}

Juvenile arthritis, Symptom assessment, Childhood, Sickness impact profile. 